\title{
Persistence and Opacity in Eastern Andalusian Harmony
}

\author{
Aaron Kaplan \\ University of Utah
}

\section{Introduction}

Positional Licensing constraints militate against features that do not coincide with a particular prominent "licensing" position, such as a stressed syllable (Walker, 2011). Constraints of this sort can drive a range of phonological processes including vowel harmony: one way to escape a violation of Positional Licensing is to spread the relevant feature to the licensing position. Walker (2011) presents a number of phenomena that exemplify harmony of this sort. In the Romance variety of Lena, for example, a suffix's [+high] spreads to the stressed syllable, skipping over vowels appearing between the trigger and target (throughout, underlining marks harmonic vowels): [trwíbanu] 'beehive (M SG)'; cf. [trwébanos] 'beehive (M PL).' Similarly, in the Romance variety of Central Veneto, post-tonic [+high] spreads to the stressed syllable, but this time intervening vowels harmonize: [úrdini]] 'order (2SG PRS IND)'; cf. [órdeno] 'order (1SG).' In both cases, once [+high] reaches the stressed syllable, Positional Licensing is satisfied.

A prediction, therefore, is that if for some reason the licensing position cannot harmonize, no harmony will occur at all. Harmony that fails to reach the licensor merely incurs faithfulness violations without remediating the violation of Positional Licensing. This prediction is borne out by nearly all of the phenomena that Walker examines for which relevant data is available. For example, low vowels do not harmonize in Central Veneto, and we therefore find [ángoli] 'angle (M PL)' rather than *[ánguli]. (See Mascaró (2019) for a different view of the facts just presented.) In this paper I examine the lone counterexample to this prediction that I am aware of. The case is presented by ATR harmony in Eastern Andalusian, where failure to harmonize the licensor (the stressed vowel) does not impede harmony in other positions. If the licensor cannot harmonize, unstressed syllables may still harmonize as normal; harmony thus overapplies to unstressed syllables in a derivationally opaque fashion. I will argue that the formal constructs necessary to account for Eastern Andalusian's harmony in Harmonic Grammar (HG; e.g. Legendre et al. 1990) make available a novel approach to this opacity. The analysis is couched in serial HG, which we will see is needed for Positional Licensing to function properly in HG. Serialism presents the opportunity for a Duke-of-York derivation (Pullum, 1976) in which the stressed syllable harmonizes to facilitate harmony on unstressed syllables, and then harmony is retracted off the stressed syllable, leaving harmony in other positions unchanged. As we will see, this requires an innovation that I will call persistence: Positional Licensing must treat the harmonizing feature as licensed even after it vacates the licensor.

\section{ATR Harmony}

ATR harmony in Eastern Andalusian (Jiménez \& Lloret, 2007; Lloret \& Jiménez, 2009; Lloret, 2018; Zubizarreta, 1979) begins with the well-known process of /s/-aspiration, whereby a word-final /s/ deletes. ${ }^{1}$ A consequence of /s/-aspiration is that the now-word-final vowel becomes lax; this laxness (i.e. [-ATR]) spreads to the stressed syllable. Examples are shown in (1), where the orthography reveals that each word

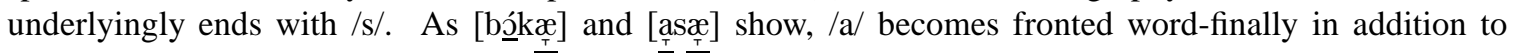
becoming lax; I will not address fronting here.

\footnotetext{
* I am grateful to the AMP 2020 participants, and especially to Eric Baković, Rachel Walker, and Ed Rubin, for their feedback on this work.

1 This characterization of /s/-aspiration simplifies matters somewhat. For example, /s/ may instead become [h]. In some dialects /s/-aspiration occurs in all codas, not just word-final ones, and it may affect consonants other than /s/. See the work just cited for details.
}

(C) 2021 Aaron Kaplan

Proceedings of AMP 2020 
(1)

\begin{tabular}{|c|c|c|}
\hline tesis & tésI & 'thesis' \\
\hline nenes & nÉn $\underline{\varepsilon}$ & 'babies' \\
\hline tienes & tjóng & 'you have' \\
\hline monos & móñ & 'monkeys' \\
\hline lejos & léhh $\underline{\partial}$ & 'far' \\
\hline pesos & p $\underline{\varepsilon} \underline{S} \underline{\underline{y}}$ & 'weights' \\
\hline bocas & bók & 'mouths' \\
\hline asas & & 'handles' \\
\hline
\end{tabular}

Harmony on a stressed non-high vowel is obligatory; see below for the facts regarding high vowels. Nonhigh unstressed vowels optionally harmonize. Non-final post-tonic vowels are illustrated in ( $2 \mathrm{a})$. If there is more than one non-final post-tonic vowel, their harmony is coordinated, as cómetelos shows: either they all harmonize, or none does. With this optionality, Eastern Andalusian exhibits variation between the behavior of Lena's unstressed vowels (which do not harmonize) and Central Veneto's (which do harmonize). Pretonic vowels show the same optionality and coordination (2 b). Furthermore, post-tonic harmony is a prerequisite for pretonic harmony: as recógelos shows, pretonic vowels cannot harmonize unless any non-final post-tonic vowels also do so. The optionality seen in (2) will not be dealt with here; see Jiménez \& Lloret (2007); Lloret \& Jiménez (2009); Lloret (2018) and Walker (2011) for Optimality Theoretic (Prince \& Smolensky, 1993/2004) accounts of this optionality, and see Kaplan (2019) for ways to account for the optionality in HG.

(2)
(a)

$$
\begin{aligned}
& \text { treboles } \\
& \text { cómetelos }
\end{aligned}
$$

\begin{tabular}{|c|c|}
\hline momentos & 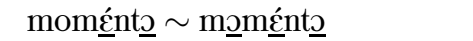 \\
\hline tenemos & 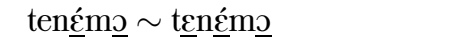 \\
\hline relojes & relóh $\underline{\underline{\varepsilon}} \sim \operatorname{r} \underline{\varepsilon} \underline{l o ́} h \underline{\varepsilon}$ \\
\hline monederos & 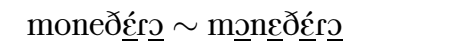 \\
\hline recógelos & 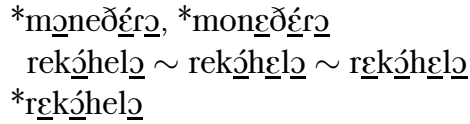 \\
\hline
\end{tabular}

(b)

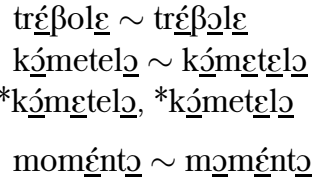

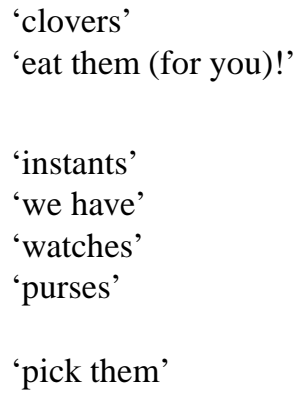

The pretonic harmony in ( 2 b) is unusual in Positional Licensing phenomena (Walker, 2011). Typically, once harmony reaches the licensor, it stops: Positional Licensing has been satisfied, and further spreading only incurs more faithfulness violations. For this reason, OT analyses of Eastern Andalusian (Jiménez \& Lloret, 2007; Lloret \& Jiménez, 2009; Lloret, 2018; Walker, 2011) invoke two licensing constraints. One, a standard Positional Licensing constraint, motivates harmony up to and including the stressed syllable. The second, a Maximal Licensing constraint (Walker, 2011), triggers pretonic harmony by requiring [-ATR] to appear in every syllable. By allowing variation in the constraint ranking (Anttila, 2007), the various options shown above can be produced.

High vowels behave somewhat differently, as illustrated in (3). These vowels become lax word-finally, but they do not undergo harmony in other positions, even when stressed (which is normally a position that obligatorily harmonizes). However, they are transparent to harmony: their invariance does not prevent other vowels from harmonizing as normal. These other vowels behave as if the high vowel had harmonized or could have harmonized.

\begin{tabular}{|c|c|}
\hline crisis & krísI \\
\hline muchos & múf $\underline{\underline{\rho}}$ \\
\hline mios & mís \\
\hline ídolos & 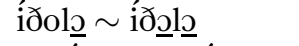 \\
\hline cojines & kohing $\underline{\varepsilon} \sim$ kohin $\underline{\varepsilon}$ \\
\hline cotillones & kotiz̧ón $\underline{\underline{\varepsilon}} \sim$ kôtizón $\underline{\underline{\varepsilon}}$ \\
\hline
\end{tabular}

(3)

$$
\begin{aligned}
& \text { 'crisis' } \\
& \text { 'many' } \\
& \text { 'mine (PL)' } \\
& \text { 'idols' } \\
& \text { 'pillows' } \\
& \text { 'cotillions' }
\end{aligned}
$$

Most relevantly for present purposes, disharmonic stressed vowels do not preclude harmony elsewhere. In contrast with [ángoli] 'angle (M PL)' from Central Veneto, [íð밈] 'idols’ shows that in Eastern Andalusian, 
when the licensor cannot harmonize, non-licensing positions-both pretonic and post-tonic-may still harmonize.

It is these forms, with disharmonic stressed vowels but harmonic unstressed vowels, that the analysis below is concerned with. The transparency of stressed high vowels gives rise to derivational opacity because harmony overapplies on unstressed vowels; recall that absent harmony on the licensor, Positional Licensing gives no incentive to harmonize non-licensing positions. The OT analyses cited above cope with this opacity via their Maximal Licensing constraint, which steps in to trigger harmony where the conventional licensing constraint cannot. Thus Maximal Licensing serves two roles, triggering both pretonic harmony and opaque harmony. While this arrangement correctly accounts for the facts, it obscures the opaque nature of the harmony in question and disperses the motivation for harmony in the sense that with two constraints triggering harmony, the language has, formally speaking, two different but suspiciously similar harmony systems.

We will see that Positional Licensing in HG triggers pretonic harmony on its own, so Maximal Licensing's job is reduced to shoring up the opaque data. Under that circumstance, the suboptimality of the Maximal Licensing-based approach to opaque harmony is plainly evident, and the need for a different approach to the issue becomes clear.

\section{Opaque Harmony in HG}

3.1 Positional Licensing in $H G$ Whereas standard Positional Licensing assigns a single violation to an unlicensed feature (i.e. for Eastern Andalusian, [-ATR] that does not appear in the stressed syllable), in other work (Kaplan, 2018b) I have argued that HG necessitates the formalism in (4). This constraint is positive and gradient: it rewards licensed features instead of penalizing unlicensed ones, and that reward escalates with the number of positions beyond the licensor that [-ATR] appears in.

(4) $\operatorname{LiCENSE}([-\mathrm{ATR}], \sigma)$ : For each [-ATR] that coincides with $\sigma$, assign +1 for each syllable that this $[-\mathrm{ATR}]$ appears in.

The advantage of this constraint is that it avoids a pernicious gang effect that arises under standard Positional Licensing in HG. In a Central Veneto-style system (where positions between the trigger and target harmonize), if the harmonizing feature must spread across a distance to reach its licensor, this harmony incurs some number of faithfulness violations as the cost of removing a single Positional Licensing violation. Eventually, regardless of the weights of Positional Licensing and faithfulness, violations of the latter will gang up on the former to preclude harmony beyond a certain distance; such systems appear not to exist. The gradient constraint in (4) avoids this problem because as the number of faithfulness violations increases, so does Positional Licensing's reward.

This new version of Positional Licensing motivates harmony in non-licensing positions. Each syllablewhether pretonic or post-tonic - to which [-ATR] spreads earns +1 , so we no longer require Maximal Licensing to provide pretonic harmony. ${ }^{2}$ However, these rewards for non-licensing positions do not appear unless the licensor itself harmonizes; this property of (4) derives Central Veneto's [ángoli], but it also means

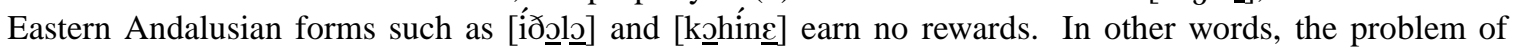
opaque harmony remains.

It would, of course, be possible to invoke Maximal Licensing to give us harmony in these cases, but doing so would only sidestep (and call attention to) the problem. I propose instead that we confront the issue directly. The next section develops a way of doing just that.

3.2 Persistent Licensing Because the Positional Licensing formalism presented in (4) is positive, it is susceptible to the "infinite goodness" problem identified by Kimper (2011): the best strategy for maximizing the reward from Positional Licensing is to epenthesize infinitely many harmonic vowels. Kimper's remedy is serialism: in serial HG, only one change is permitted on any step, so we cannot both epenthesize and harmonize a vowel. Epenthesis must occur first, but there is no motivation for epenthesis absent harmony (a disharmonic epenthetic vowel only gratuitously violates DEP), so the path toward infinite epenthesis is blocked.

2 See Kaplan (2018b) for an explanation of how (4) can yield Lena-style harmony in which non-licensing positions do not harmonize. As for arresting harmony at the licensor, in Kaplan (2018a) I argue for a CRISPEDGE constraint (Ito \& Mester, 1999) preventing the licensor from sharing the harmonizing feature with syllables to left. 
The derivation in (5) shows how positive gradient Positional Licensing produces harmony when opacity is not an issue. To yield harmony on unstressed syllables, LICENSE must outweigh * [-ATR $]^{3}$ If high vowels are to resist harmony, ${ }^{*}[+$ hi, - ATR] (e.g. Archangeli \& Pulleyblank 1994) must in turn outweigh LiCENSE. The derivation begins after/s/-aspiration and final laxing. The next step at that point is to harmonize the licensor; harmony in other positions earns no reward yet. (Throughout, I assume MAX(-ATR) prevents deletion of [-ATR].) The non-high pretonic vowel subsequently harmonizes, and the derivation converges there; extending harmony to /i/ is blocked by *[+hi, -ATR].

(a) Step 1

\begin{tabular}{|c|c|c|c|c|}
\hline /kotizóne/ & $*\left[+\mathrm{hi},{ }_{6}, \mathrm{ATR}\right]$ & $\begin{array}{c}\text { LICENSE } \\
5 \\
\end{array}$ & $*[-\mathrm{ATR}]$ & $H$ \\
\hline a. kotizón $\underline{\varepsilon}$ & & & -1 & -1 \\
\hline b. kotizón $\underline{\underline{\varepsilon}}$ & & +2 & -2 & 8 \\
\hline c. kôtizón $\underline{\varepsilon}$ & & & -2 & -2 \\
\hline d. kotızón $\underline{\varepsilon}$ & -1 & & -2 & -8 \\
\hline
\end{tabular}

(b) Step 2

\begin{tabular}{|c|c|c|c|c|}
\hline /kotizóng / & $\begin{array}{c}*[+\mathrm{hi},-\mathrm{ATR}] \\
6 \\
\end{array}$ & $\begin{array}{c}\text { LICENSE } \\
5 \\
\end{array}$ & $\begin{array}{c}*[-\mathrm{ATR}] \\
1 \\
\end{array}$ & $H$ \\
\hline a. kotizóng $\underline{\varepsilon}$ & & +2 & -2 & 8 \\
\hline b. kㅁtizón $\underline{\underline{\varepsilon}}$ & & +3 & -3 & 12 \\
\hline c. kotizón $\underline{\varepsilon}$ & & & -1 & -1 \\
\hline d. kotızón $\underline{\varepsilon}$ & -1 & +3 & -3 & 6 \\
\hline
\end{tabular}

(c) Step 3: Convergence

\begin{tabular}{|c|c|c|c|c|}
\hline /kḡtizóng / & $*[+\mathrm{hi}, \underset{6}{-\mathrm{ATR}}]$ & $\begin{array}{l}\text { LICENSE } \\
5\end{array}$ & $*[-\underset{1}{\mathrm{ATR}}]$ & $H$ \\
\hline a. kotizón $\underline{n} \underline{\varepsilon}$ & & +3 & -3 & 12 \\
\hline 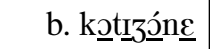 & -1 & +4 & -4 & 10 \\
\hline c. kotizón $\underline{\varepsilon}$ & & +2 & -2 & 8 \\
\hline
\end{tabular}

However, when the stressed vowel is high, the derivation fails. In (6), LICENSE's weight is great enough that it can overcome *[+hi, -ATR] to produce harmony on the stressed syllable, which subsequently facilitates harmony elsewhere. However, retracting harmony off the stressed syllable after unstressed syllables have harmonized is not feasible because doing so sacrifices all the rewards from LICENSE, not just the stressed syllable's reward. The analysis favors an illicit transparent candidate (marked by $)$ over the attested opaque one (marked by ( $)$ ).

(6)

(a) Step 1

\begin{tabular}{|c|c|c|c|c|}
\hline /íðolı_/ & $*[+$ hi, $\underset{6}{- \text { ATR }}]$ & $\begin{array}{c}\text { LICENSE } \\
5\end{array}$ & $*[-\mathrm{ATR}]$ & $H$ \\
\hline 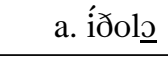 & & & -1 & -1 \\
\hline 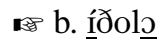 & -1 & +2 & -2 & 2 \\
\hline 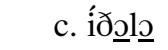 & & & -2 & -2 \\
\hline
\end{tabular}

\footnotetext{
3 Because Eastern Andalusian has no lax vowels aside from those resulting from /s/-aspiration and harmony, *[-ATR] must outweigh IDENT(ATR). Therefore, $*[-\mathrm{ATR}]$ is the principal constraint militating against harmony in the language.
} 
(b)

\begin{tabular}{|c|c|c|c|c|}
\hline /İðolọ/ & $*[+$ hi, $\underset{6}{* \text { ATR }]}$ & $\begin{array}{c}\text { LICENSE } \\
5 \\
\end{array}$ & $\begin{array}{c}* \text { [-ATR }] \\
1 \\
\end{array}$ & $H$ \\
\hline a. Í đolol $\underline{\mathrm{p}}$ & -1 & +2 & -2 & 2 \\
\hline b. Ífộlo & -1 & +3 & -3 & 6 \\
\hline c. íðolo & & & -1 & -1 \\
\hline
\end{tabular}

(c) Step 3: Convergence

\begin{tabular}{|c|c|c|c|c|}
\hline 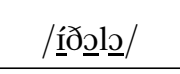 & $\frac{*[+h i,-\mathrm{ATR}]}{6}$ & $\begin{array}{c}\text { LICENSE } \\
5 \\
\end{array}$ & $\begin{array}{c}*[-\mathrm{ATR}] \\
1\end{array}$ & $H$ \\
\hline 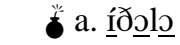 & -1 & +3 & -3 & 6 \\
\hline ( b. íd $\underline{\text { (d) }} \underline{\mathrm{a}}$ & & & -2 & -2 \\
\hline
\end{tabular}

On the other hand, if the weights preclude harmony on the stressed syllable, as in (7), the derivation immediately converges on the candidate with no harmony. This is an attested output, but the alternative [íðọlo $]$ cannot be produced.

\begin{tabular}{|c|c|c|c|c|}
\hline & & & IDENT & \\
\hline /iðolㅁ/ & $\begin{array}{c}{[\mathrm{THI},-\mathrm{R}]} \\
\end{array}$ & $\begin{array}{l}5 \\
5\end{array}$ & $\begin{array}{c}\text { IDEIN I } \\
1 \\
\end{array}$ & $H$ \\
\hline a. íđolo & & & -1 & -1 \\
\hline ( b. íd & & & -2 & -2 \\
\hline c. Íðol’ $\underline{a}$ & -1 & +2 & -2 & -3 \\
\hline
\end{tabular}

In [íðo $\underline{\text { İo] }}$, the unstressed vowel behaves as if the stressed vowel had harmonized. Despite the failure of (6) and (7), serialism, with the intermediate derivational stages it provides, supports an analytical approach that allows us to capture this observation. The missing piece in the final tableau in (6) is recognition that [-ATR] was licensed at an earlier stage in the derivation. If [-ATR] were to continue to count as licensed after being retracted off the licensor, LICENSE would continue to reward it, and the correct outcome would emerge from (6). Candidate (b) in Step 3 would earn +2 from LiCEnsE, adding 10 to its harmony score. However, we need some way to distinguish features that were once licensed from those that never were-we do not want LICENSE to indiscriminately reward non-licensing positions.

For this purpose I propose persistence, the central claim of which is that once a feature is licensed, it remains so throughout the derivation. This requires adopting some way to signal that the feature in question has been licensed; I will tag such a feature with $L$-in tableaux, this $L$ will appear as a subscript on forms containing a licensed feature. See section (4) for discussion of alternatives approaches. The following constraint enforces $L$ 's presence.

PERSISTENCE: assign -1 if $[-\mathrm{ATR}]$ is in $\sigma$ and lacks $L$.

A change to LICENSE is also needed. It must reward both currently and formerly licensed features:

(9) LICENSE([-ATR], $\sigma)$ : For each [-ATR] that coincides with $\sigma$ or bears $L$, assign +1 for each syllable that this $[-\mathrm{ATR}]$ appears in.

The derivation now succeeds. Once again, (10) picks up after /s/-aspiration and final laxing. In Step 1, harmony targets the stressed syllable as normal, and PERSISTENCE ensures that the winning candidate bears L. In Step 2, the non-final unstressed vowel harmonizes. Step 3 is the crucial step: in contrast with (6c), retraction of harmony off the stressed vowel is now possible. Via persistence, LICENSE's rewards for the unstressed vowels remain and the eventual surface form wins. Retracting harmony now sacrifices only the stressed vowel's reward, not every vowel's reward. The derivation converges at Step 4. 
(10)

(a) Step 1

\begin{tabular}{|c|c|c|c|c|c|}
\hline /íðol﹎./ & $*[+\mathrm{hi}, \underset{6}{-\mathrm{ATR}]}$ & $\begin{array}{c}\text { LICENSE } \\
5 \\
\end{array}$ & $\begin{array}{c}*[-\mathrm{ATR}] \\
1 \\
\end{array}$ & $\begin{array}{c}\text { PERSISTENCE } \\
1 \\
\end{array}$ & $H$ \\
\hline 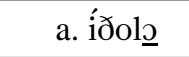 & & & -1 & & -1 \\
\hline b. $\underline{1} \partial o \underline{\mathbf{p}}_{L}$ & -1 & +2 & -2 & & 2 \\
\hline 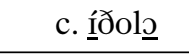 & -1 & +2 & -2 & -1 & 1 \\
\hline 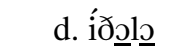 & & & -2 & & -2 \\
\hline
\end{tabular}

(b) Step 2

\begin{tabular}{|c|c|c|c|c|c|}
\hline 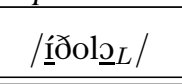 & $*[+\mathrm{hi}, \underset{6}{-\mathrm{ATR}}]$ & $\begin{array}{c}\text { LICENSE } \\
5 \\
\end{array}$ & $\begin{array}{c}*[-\mathrm{ATR}] \\
1\end{array}$ & $\begin{array}{c}\text { PERSISTENCE } \\
1 \\
\end{array}$ & $H$ \\
\hline 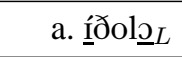 & -1 & +2 & -2 & & 2 \\
\hline 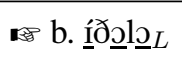 & -1 & +3 & -3 & & 6 \\
\hline c. íðolol $\underline{p}_{L}$ & & +1 & -1 & & 4 \\
\hline
\end{tabular}

(c) Step 3

\begin{tabular}{|c|c|c|c|c|c|}
\hline /İ $\underline{\rho}_{\mathrm{s}} \underline{\mathrm{p}}_{L} /$ & $*[+\mathrm{hi}, \underset{6}{-\mathrm{ATR}]}$ & $\begin{array}{c}\text { LICENSE } \\
5 \\
\end{array}$ & $*\left[\begin{array}{c}-\mathrm{ATR}] \\
1\end{array}\right.$ & $\begin{array}{c}\text { PERSISTENCE } \\
1 \\
\end{array}$ & $H$ \\
\hline 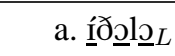 & -1 & +3 & -3 & & 6 \\
\hline 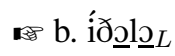 & & +2 & -2 & & 8 \\
\hline
\end{tabular}

(d) Step 4: Convergence

\begin{tabular}{|c|c|c|c|c|c|}
\hline 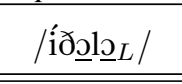 & $\frac{*[+\mathrm{hi},-\mathrm{ATR}]}{6}$ & $\begin{array}{c}\text { LICENSE } \\
5 \\
\end{array}$ & $\begin{array}{c}*[-\mathrm{ATR}] \\
1 \\
\end{array}$ & $\begin{array}{c}\text { PERSISTENCE } \\
1 \\
\end{array}$ & $H$ \\
\hline$\Leftrightarrow$ a. íðo $\underline{\mathbf{l}} \underline{\mathbf{p}}_{L}$ & & +2 & -2 & & 8 \\
\hline b. $\underline{\text { Í}} \partial \underline{\mathrm{g}} \underline{\mathrm{l}} \underline{\mathrm{D}} L$ & -1 & +3 & -3 & & 6 \\
\hline c. íðolol $\underline{D}_{L}$ & & +1 & -1 & & 4 \\
\hline
\end{tabular}

The weighting requirements for this derivation are given in (11). The inequality in (11 a) gives us harmony on the stressed syllable (10 a). Because the winning candidate in that tableau earns +2 from LICENSE at the expense of just a new -1 from each of $*[+h i,-A T R]$ and $*[-A T R]$ compared to the faithful candidate (a), LICENSE need not outweigh these constraints; having more than half their summed weights is sufficient. Harmony on unstressed vowels $(10 \mathrm{~b})$ results from $(11 \mathrm{~b})$, and $(11 \mathrm{c})$ is responsible for the retraction of harmony off the stressed syllable $(10 \mathrm{c})$.

(a) $2 * w($ LICENSE $)>w(*[+\mathrm{hi},-\mathrm{ATR}])+w(*[-\mathrm{ATR}])$

(b) $w$ (LICENSE) $>w(*[-\mathrm{ATR}])$

(c) $w(*[+\mathrm{hi},-\mathrm{ATR}])+w(*[-\mathrm{ATR}])>w($ LICENSE $)$

The analysis succeeds because (10 a) and (10 c) are asymmetrical. Harmonizing the stressed syllable in (10 a) earns +2 from LICENSE (which is enough to overcome *[+hi, -ATR]), but because persistence allows us to retain some rewards when others are lost, $*[+h i,-A T R]$ can force harmony off the stressed syllable in $(10 \mathrm{c})$, sacrificing just one of LICENSE's rewards. Harmony on stressed high vowels need not be permanent: these vowels may harmonize to facilitate harmony elsewhere and thereby maximize LICENSE's reward, and they may subsequently become disharmonic to minimize *[+hi, -ATR]'s penalty.

However, the analysis does not impose this Duke-of-York-style derivation on all high vowels. As (12) shows, the derivation from (5) is essentially unchanged. The stressed vowel harmonizes on Step 1, the nonhigh pretonic vowel harmonizes on Step 2, and the derivation converges without /i/ undergoing harmony. This time, harmony on /i/ earns just +1 from LICENSE-this harmony is not a prerequisite for rewards earned by other vowels — and it is blocked by *[+hi, -ATR]. 
(a)

\begin{tabular}{|c|c|c|c|c|c|}
\hline /kotizóne/ & $*[+$ hi, - ATR $]$ & $\begin{array}{c}\text { LICENSE } \\
5 \\
\end{array}$ & $\begin{array}{c}*[-\mathrm{ATR}] \\
1 \\
\end{array}$ & $\begin{array}{c}\text { PERSISTENCE } \\
1 \\
\end{array}$ & $H$ \\
\hline a. kotizón $\underline{\varepsilon}$ & & & -1 & & -1 \\
\hline 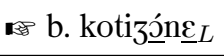 & & +2 & -2 & & 8 \\
\hline c. kotizón $\underline{\varepsilon}$ & & +2 & -2 & -1 & 7 \\
\hline d. kọtizón & & & -2 & & -2 \\
\hline e. kotızón $\underline{\varepsilon}$ & -1 & & -2 & & -8 \\
\hline
\end{tabular}

(b) Step 2

\begin{tabular}{|c|c|c|c|c|c|}
\hline /kotizón $\underline{\varepsilon}_{L} /$ & $*[+\mathrm{hi}, \underset{6}{6}-\mathrm{ATR}]$ & $\begin{array}{c}\text { LICENSE } \\
5\end{array}$ & $*\left[\begin{array}{c}-\mathrm{ATR} \\
1\end{array}\right.$ & $\begin{array}{c}\text { PERSISTENCE } \\
1\end{array}$ & $H$ \\
\hline a. kotizóng $\underline{\varepsilon}_{L}$ & & +2 & -2 & & 8 \\
\hline b. kg̣tizón $\underline{\varepsilon}_{L}$ & & +3 & -3 & & 12 \\
\hline c. kotizón $\underline{\varepsilon}_{L}$ & & +1 & -1 & & 4 \\
\hline 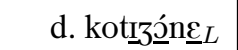 & -1 & +3 & -3 & & 6 \\
\hline
\end{tabular}

(c) Step 3: Convergence

\begin{tabular}{|c|c|c|c|c|c|}
\hline /kㅁtizóng $\underline{\varepsilon}_{L} /$ & $\begin{array}{c}*[+\mathrm{hi},-\mathrm{ATR}] \\
6 \\
\end{array}$ & $\begin{array}{c}\text { LICENSE } \\
5 \\
\end{array}$ & $\begin{array}{c}* \text { [-ATR }] \\
1 \\
\end{array}$ & $\begin{array}{c}\text { PERSISTENCE } \\
1 \\
\end{array}$ & $H$ \\
\hline a. kㅁtizón $\underline{n} \underline{\varepsilon}_{L}$ & & +3 & -3 & & 12 \\
\hline 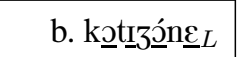 & -1 & +4 & -4 & & 10 \\
\hline c. $\operatorname{koti} 3 \underline{\underline{n}} \underline{\varepsilon}_{L}$ & & +2 & -2 & & 8 \\
\hline d. kọtizón $\underline{\varepsilon}_{L}$ & & +2 & -2 & & 8 \\
\hline
\end{tabular}

By changing constraints' weights, it is also possible to produce transparent harmony. Harmony that disregards vowel height and targets every vowel results when LICENSE outweighs the sum of *[+hi, -ATR] and *[-ATR]. And Central Veneto-style harmony in which disharmonic stressed vowels block harmony elsewhere emerges when the combination of * [+hi, -ATR $]$ and * [-ATR] has more than double LICENSE's weight.

To reiterate, the analysis developed here does not account for the optionality presented by Eastern Andalusian. But it is easy to see how optionality can be accommodated in Noisy HG (Jesney, 2007; Hayes, 2017) or some other framework that allows constraint weights to vary. To sketch the Noisy HG analysis of Kaplan (2019), when LICENSE and *[-ATR] have sufficiently similar weights, perturbing those weights with noise allows both $(11 \mathrm{~b}$ ), which generates harmony on unstressed syllables, and its opposite (which precludes that harmony). Similarly, variation in the weight of the CRISPEDGE constraint that can block pretonic harmony (see fn. 2) accounts for pretonic vowels: with a sufficiently high weight, CRISPEDGE prevents pretonic harmony (even if post-tonic unstressed vowels harmonize), and with a low weight it permits pretonic harmony.

\section{Discussion}

This analysis has much in common with Turbidity (Goldrick, 2000), a framework that produces opacity in a parallel system by allowing constraints to be satisfied by a covert level of representation. Like Turbidity, persistence effectively allows reference to a construct besides the surface form. The chief difference between the theories is that while Turbidity introduces a new covert form, persistence makes use of the intermediate forms inherent to serial frameworks.

In the analysis above, persistence is formalized as a marker that is acquired by a feature when it reaches its licensor and that is retained for the remainder of the derivation. This is not the only possibility, of course. All that is necessary is that upon reaching the stressed syllable, [-ATR] must undergo some change (or trigger a change elsewhere in the form) that can be identified later in the derivation. One particularly intriguing option draws inspiration from the feature-checking system employed in Minimalist syntax (Chomsky, 1995). 
In this approach, [-ATR] would bear an uninterpretable feature that must be checked by a stressed syllable. Positional Licensing, then, reduces to a requirement that features be checked; formally speaking, it would assign +1 for every syllable that hosts a [-ATR] bearing no uninterpretable feature. As in syntactic analyses, once this uninterpretable feature is checked, $[-\mathrm{ATR}]$ is under no obligation to remain in the feature-checking position, and $*[+h i,-$ ATR $]$ can force it to vacate the stressed syllable. Perhaps exactly the same constraint drives harmony that targets different licensing positions (say, initial syllables or roots; see Walker (2011) and Kaplan (2015) for discussion) in other languages; the harmonizing features in those systems simply bear features that must be checked by something other than the stressed syllable. Obviously, important questions concerning this feature-checking implementation of persistence remain unanswered (e.g., what exactly is the uninterpretable feature?), but it might achieve the desired result solely by adopting formal constructs used elsewhere in linguistics.

Another issue to consider is the range of output patterns that persistence makes possible. For example, persistence allows the coexistence of two different kinds of harmony-resistant licensors: one that behaves like Eastern Andalusian's high vowels and another whose failure to harmonize blocks harmony elsewhere (as predicted by traditional Positional Licensing). Such a system would emerge were we to decompose *[+hi, $-\mathrm{ATR}]$ into $*_{I}$ and $*_{v}$ and assign these constraints crucially different weights. Giving $*_{I}$ the weight $*[+$ hi, -ATR] has in the analysis above would produce the same results seen in (10) and (12), while a weight greater than 7 for $*_{\mho}$ would prevent $/ \mathrm{u} /$ from harmonizing at all, even temporarily when stressed. The hypothetical input /úðolos/ would surface invariantly as [úðolı]]: the analog of (10a), where the stressed vowel harmonizes, would be impossible. Unfortunately, I am aware of no data showing whether stressed /u/ precludes other harmony in Eastern Andalusian; the only forms with final lax vowels and stressed /u/ that I am aware of are disyllabic (e.g. [mú $\underline{\jmath}$ ] 'many' from (3)) and thus have no unstressed potential targets of harmony. To be clear, persistence does not predict that /u/ behaves differently from /i/; it merely makes that situation possible, both in Eastern Andalusian and in any other licensing-based harmony system. Whether this pattern is attested remains to be seen.

Perhaps more concerning is the possibility of a feature that never surfaces in its licensing position but otherwise behaves as if it did. A situation like this might emerge from competition between Positional Licensing and positional augmentation constraints (Smith, 2005), which require prominent positions to be filled by prominence-enhancing elements. High vowels can be subject to both constraint types: the metaphony system of Central Veneto is a Positional Licensing system in which [+high] spreads to the stressed syllable (Walker, 2011), and Zabiče Slovene requires high-sonority stressed vowels and consequently bans [+high] from the stressed syllable (see Smith (2005) and references therein). Persistent Positional Licensing therefore predicts a language in which [+high] spreads to the stressed syllable and then to unstressed syllables for licensing purposes, then vacates the stressed syllable to comply with the ban on high unstressed vowels. On the surface, no vowel in a word (or a smaller domain, such as post-tonic vowels as in Central Veneto and other Romance metaphony systems) could surface as high unless all unstressed vowels do, while stressed syllables would be banned from hosting a high vowel. In other words, the licensor would be the only position that cannot host the feature whose harmony Positional Licensing triggers. A system like this seems a priori implausible; it is possible that it would turn out to be unlearnable or perhaps sufficiently similar to other harmony types as to be mistaken (either by the analyst or the learner) for them. Interactions between different families of position-sensitive constraints likes Positional Licensing and positional augmentation have not been fully explored in general, and it seems unlikely that unwanted outcomes from these interactions arise only in the context of persistence.

Applied more generally, persistence grants serial HG significant power, and pathological outcomes may result. But in at least some cases, an apparent pathology reduces to a well-attested pattern. For example, a persistence-enabled *NC (Pater, 1999) invites the following pattern when (i) it outweighs the combination of *Voicedobstruent and Ident(voi), and (ii) *VoicedObstruent outweighs Ident(voi). Underlying $\mathrm{NC}$ sequences are preserved on the surface by way of voicing and then devoicing $\mathrm{C}(13)$, whereas underlying NC does not change at all (14). This is an odd way to produce a postnasal voicing contrast, but that is all the system reduces to. To be clear about the mechanics of the analysis, PERSISTENCE now requires a *NCcompliant candidate to be marked with $p$ (which I use here rather than $L$ because Positional Licensing is not involved), and ${ }^{*} \mathrm{NC}$ penalizes only $\mathrm{NC}$ s sequences that are not tagged with $p$. 
(a)

\begin{tabular}{|c|c|c|c|c|c|}
\hline /onk/ & $\begin{array}{c}* \mathrm{NC} \\
4\end{array}$ & *VOICEDOBSTRUENT & $\begin{array}{c}\text { IDENT(voi) } \\
1 \\
\end{array}$ & $\begin{array}{c}\text { PERSISTENCE } \\
1 \\
\end{array}$ & $H$ \\
\hline a. opk & -1 & & & & -4 \\
\hline b. ong $p$ & & -1 & -1 & & -3 \\
\hline c. ong & & -1 & -1 & -1 & -4 \\
\hline
\end{tabular}

(b) Step 2

\begin{tabular}{|c|c|c|c|c|c|}
\hline$/ \operatorname{ong}_{p} /$ & $\underset{4}{* \mathrm{NC}}$ & *VOICEDOBSTRUENT & $\begin{array}{c}\text { IDENT(voi) } \\
1\end{array}$ & $\begin{array}{c}\text { PERSISTENCE } \\
1\end{array}$ & $H$ \\
\hline a. ong $p$ & & -1 & & & -2 \\
\hline $\mathrm{b}$. olj $\mathrm{k}_{p}$ & & & -1 & & -1 \\
\hline
\end{tabular}

(c) Step 3: Convergence

\begin{tabular}{|c|c|c|c|c|c|}
\hline$/ \mathrm{ogk}_{p} /$ & $\begin{array}{c}* \mathrm{NC} \\
4\end{array}$ & *VOICEDOBSTRUENT & $\begin{array}{c}\text { IDENT(voi) } \\
1 \\
\end{array}$ & $\begin{array}{c}\text { PERSISTENCE } \\
1\end{array}$ & $H$ \\
\hline a. olk $\mathrm{k}_{p}$ & & & & & 0 \\
\hline b. oyg $g_{p}$ & & -1 & -1 & & -3 \\
\hline
\end{tabular}

(14) Step 1: Convergence

\begin{tabular}{|c|c|c|c|c|c|}
\hline /ong/ & $\begin{array}{c}* \mathrm{NC} \\
4\end{array}$ & *VOICEDOBSTRUENT & $\begin{array}{c}\text { IDENT(voi) } \\
1\end{array}$ & $\begin{array}{c}\text { PERSISTENCE } \\
1\end{array}$ & $H$ \\
\hline a. onk & -1 & & -1 & & -5 \\
\hline b. ong $p$ & & -1 & & & -2 \\
\hline
\end{tabular}

\section{Conclusion}

Ordinarily, serial constraint-based frameworks must evaluate the candidates at each step oblivious to what occurred on previous steps or what might happen on subsequent steps-these theories have neither lookback nor look-ahead capabilities. But opacity of the sort presented by Eastern Andalusian challenges this restriction. Persistence allows us to refrain from granting serial HG genuine look-back while also producing the kind of overapplication that look-back itself would generate: a process (harmony on unstressed syllables) that has applied despite the conditions for it (harmony on the stressed syllable) being absent. With look-back, the theory could peer into earlier steps to ascertain whether [-ATR] ever appeared in the stressed syllable; persistence allows the results of those earlier steps to be carried into the present step, obviating look-back.

Eastern Andalusian's [ATR] harmony is clearly a licensing-based system, as revealed by the fact that the stressed syllable is the only position that harmony obligatorily targets. But it also disobeys generalizations that hold for most licensing-based patterns: optionality, pretonic harmony (more precisely, harmony that does not stop once the licensor is reached), and the possibility of harmony on non-licensors absent harmony on the licensor are all typologically unusual. Persistence provides an account of one of these characteristics that does not disrupt our ability to account for the more typical kind of licensing-based harmony found in other languages.

\section{References}

Anttila, Arto (2007). Variation and optionality. de Lacy, Paul (ed.), The Cambridge Handbook of Phonology, Cambridge University Press, Cambridge, 519-536.

Archangeli, Diana \& Douglas Pulleyblank (1994). Grounded Phonology. MIT Press, Cambridge, MA.

Chomsky, Noam (1995). The Minimalist Program. The MIT Press, Cambridge, MA.

Goldrick, Matt (2000). Turbid output representations and the unity of opacity. Hirotani, M, A Coetzee, N Hall \& J.-Y Kim (eds.), NELS 30, GLSA, Amherst, MA.

Hayes, Bruce (2017). Varieties of noisy HG. Jesney, Karen, Charlie O’Hara, Caitlin Smith \& Rachel Walker (eds.), Proceedings of AMP 2016, Linguistic Society of America, Washington, DC.

Ito, Junko \& Armin Mester (1999). Realignment. Kager, René, Harry van der Hulst \& Wim Zonneveld (eds.), The Prosody-Morphology Interface, Cambridge University Press, Cambridge, U.K., 188-217. 
Jesney, Karen (2007). The locus of variation in weighted constraint grammars. Poster presented at the Workshop on Variation, Gradience and Frequency in Phonology. Stanford, CA: Stanford University. July 2007.

Jiménez, Jesús \& Maria-Rosa Lloret (2007). Andalusian vowel harmony: Weak triggers and perceptibility. paper presented at the 4th Old World Conference in Phonology, Workshop on Harmony in the Languages of the Mediterranean, Rhodes, January 18-21, 2007.

Kaplan, Aaron (2015). Maximal prominence and a theory of possible licensors. NLLT 33, 1235-1270.

Kaplan, Aaron (2018a). Asymmetric crisp edge. Bennett, Ryan, Adrian Brasoveanu, Dhyana Buckley, Nick Kalivoda, Shigeto Kawahara, Grant McGuire \& Jaye Padgett (eds.), Hana-bana: A Festschrift for Junko Itô and Armin Mester, Department of Linguistics, University of California, Santa Cruz, Santa Cruz, CA, URL https://itomestercelebration.sites.ucsc.edu/.

Kaplan, Aaron (2018b). Positional licensing, asymmetric trade-offs, and gradient constraints in Harmonic Grammar. Phonology 35, 247-286.

Kaplan, Aaron (2019). Noisy HG models of Eastern Andalusian harmony. Talk presented at the Sixteenth Old World Conference in Phonology, University of Verona, Verona, Italy, January 18.

Kimper, Wendell A. (2011). Competing Triggers: Transparency and Opacity in Vowel Harmony. Ph.D. thesis, University of Massachusets, Amherst, Amherst, MA.

Legendre, Géraldine, Yoshiro Miyata \& Paul Smolensky (1990). Can connectionism contribute to syntax? harmonic grammar, with an application. Ziolkowski, Michael, Manuela Noske \& Karen Deaton (eds.), Procedings of the 26th Regional Meeting of the Chicago Linguistic Society, Chicago Linguistic Society, Chicago, 237-252.

Lloret, Maria-Rosa (2018). Andalusian vowel harmony at the phonology-morphology interface. Talk presented at the 2015 Old World Conference on Phonology, London, January 12-14.

Lloret, Maria-Rosa \& Jesús Jiménez (2009). Un análisis óptimo de la armonía vocálica del andaluz. Verba 36, $293-325$.

Mascaró, Joan (2019). On the lack of evidence for nonmyopic harmony. LI 50:4, 862-872.

Pater, Joe (1999). Austronesian nasal substitution and other NC effects. Kager, René, Harry van der Hulst \& Wim Zonneveld (eds.), The Prosody-Morphology Interface, Cambridge University Press, Cambridge, 310-343.

Prince, Alan \& Paul Smolensky (1993/2004). Optimality Theory: Constraint interaction in generative grammar. Ms., Rutgers University, New Brunswick and University of Colorado, Boulder. Published 2004, Malden, MA: Blackwell.

Pullum, Geoffrey K. (1976). The Duke of York gambit. Journal of Linguistics 12:1, 83-102.

Smith, Jennifer L. (2005). Phonological Augmentation in Prominent Positions. Routledge, New York.

Walker, Rachel (2011). Vowel Patterns in Language. Cambridge University Press, New York.

Zubizarreta, Maria Luisa (1979). Vowel harmony in Andalusian Spanish. MIT Working Papers in Linguistics 1, 1-11. 